\title{
SARAMPO: CARACTERIZAÇÃO DE CASOS NOTIFICADOS EM REGIONAL DE SAÚDE DO PARANÁ
}

\section{SARAMPO: CHARACTERIZATION OF NOTIFIED CASES IN A HEALTH REGION OF PARANÁ}

\begin{abstract}
Marcela Gonçalves Trevisan', Renata Fatima Soares de Lima Ribeiro', Géssica Tuani Teixeira', Lediana Dalla Costa'

' Universidade Paranaense (UNIPAR), Departamento de Enfermagem, Francisco Beltrão, Paraná, Brasil.
\end{abstract}

*Autor Correspondente: Endereço: Av. Júlio Assis Cavalheiro, 2000, Industrial. CEP: 85.601-000 - Francisco Beltrão, Paraná, Brasil. Telefone: (46) 3520-2800. E-mail: marcelatrevisan@unipar.br

\section{RESUMO}

Objetivo: caracterizar os casos de sarampo notificados em Regional de Saúde do interior do Paraná, Brasil. Método: pesquisa documental, retrospectiva, com abordagem quantitativa. Analisaram-se 49 notificações de sarampo, registradas no Sistema de Informação de Agravos de Notificação, entre junho de 2018 e junho de 2020. Para coleta de dados, utilizou-se de instrumento elaborado pelas pesquisadoras. Os dados foram submetidos a tratamento estatístico descritivo. Resultados: do total de casos notificados, dois $(4,1 \%)$ foram confirmados. No ano de 2019 , ocorreu o maior número de notificações $(55,1 \%)$. Houve predomínio do sexo masculino $(57,1 \%)$, com idade escolar $(36,7 \%)$ e vacinados $(59,2 \%)$. Conclusão: houve, de forma pouco incidente, a reintrodução do vírus do sarampo na Regional de Saúde pesquisada. Ao considerar que a vacinação é a principal medida de controle do sarampo, enfatiza-se a necessidade do desenvolvimento de campanhas mais efetivas e abrangentes.

Palavras-chave: Sarampo; Enfermagem; Prevenção de doenças; Sistemas de Informação em Saúde; Saúde pública.

\section{ABSTRACT}

Objective: to characterize the cases of measles reported in a Health Regional in the interior of Paraná. Method: a documentary, retrospective research, of quantitative approach. A total of 49 reports of measles, reported in the Information System for Notifiable Diseases, between June 2018 and June 2020 were analyzed. For data collection, an instrument elaborated by the researchers was used. Data were analyzed using descriptive statistics. Results: Of the total number of reported cases, only $2(4.1 \%)$ were confirmed. The maximum number of reports $(55.1 \%)$ was in 2019. There was a predominance of males $(57.1 \%)$, in school-age $(36.7 \%)$ and vaccinated (59.2\%). Conclusion: There is a resurgence of the measles virus in the Regional Health. However, in a mild way. Considering that vaccination is the most important method of measles control, the need for the development of more effective and comprehensive campaigns is highlighted. Keywords: Measles; Nursing; Disease prevention; Health Information Systems; Public Health. 


\section{INTRODUÇÃO}

O sarampo é uma patologia de causa viral aguda grave e altamente contagiosa, produzida pelo vírus Paramyxovirus, do gênero Morbillivírus. A transmissão ocorre por contato direto com secreções nasofaríngeas de indivíduos infectados, expelidas ao tossir, espirrar, falar e respirar (FERREIRA et al., 2019).

Os principais sinais e sintomas do sarampo podem ser confundidos com o de uma simples gripe, como tosse, mal-estar e coriza. No entanto, também se caracteriza por febre alta, superior a $38,5^{\circ} \mathrm{C}$, exantema maculopapular que se inicia-se entre o segundo e quarto dia da infecção, em região retroauricular e face, com progressão céfalo-caudal, e, ainda, pelas manchas de Koplik que são pequenos pontos brancos na mucosa bucal (CARVALHO et al., 2019).

A erupção do sarampo pode se manifestar em três períodos: de infecção, que tem duração de sete dias e compreende todos os sintomas pertinentes; toxêmico, em que ocorre a acentuação dos sintomas e são frequentes as complicações; e período de remissão, quando há diminuição dos sintomas e as manchas se tornam escurecidas e, muitas vezes, tem-se a presença de descamação fina (BRASIL, 2019a).

O sarampo pode trazer algumas complicações, como diarreias, otites, ceratoconjuntivites, infecções respiratórias graves, com quadro de pneumonia e alterações neurológicas, como a encefalomielite aguda disseminada (XAVIER et al., 2019). O período de incubação é de dez dias, podendo variar entre sete e dezoito dias da data de exposição e presença da febre, e quatorze dias até o começo do exantema (CARVALHO et al., 2019).

A transmissibilidade se inicia seis dias antes do exantema e tem duração de quatro dias após o surgimento, sendo o segundo dia posterior ao aparecimento do sintoma, o período em que ocorre a maior transmissibilidade(BRASIL, 2019a).

Para confirmação diagnóstica, pode-se considerar três critérios: clínico, por meio de avaliação de sinais e sintomas; laboratoriais, mediante a coleta de sangue, urina e secreção nasofaríngea; e por critérios epidemiológicos, para identificação dos casos, se autóctones ou importados. Não existe tratamento medicamentoso específico, apenas sintomático (CARVALHO et al., 2019).

Crianças de até 12 meses estão mais suscetíveis à infecção e a complicações, sendo considerada uma das principais causas de morbimortalidade e hospitalizações na infância. Sobretudo, o sarampo é relativamente raro nos primeiros seis meses, devido à transferência transplacentária de anticorpos maternos (XAVIER et al., 2019).

O maior número de casos de sarampo registrado no Brasil foi no ano de 1986, identificando a incidência de 97,7 a cada 100.000 habitantes (BRASIL, 2019b). Frente ao exposto, implantaram-se medidas de combate à doença, sendo que, em 2016, o Brasil recebeu o certificado de eliminação da circulação do vírus do sarampo pela Organização Mundial da Saúde (OMS) e a região das Américas foi declarada livre do sarampo (BRASIL, 2018).

Desde julho de 2017, a Venezuela tem vivido surto de sarampo e, devido à situação econômica e sociopolítica, no mesmo ano, houve intenso movimento migratório dos venezuelanos para diversas regiões, como o estado de Roraima no Brasil (BRANCO; MORGADO, 2019).

Em decorrência dos movimentos migratórios dos venezuelanos para Roraima, em fevereiro de 2018, o Brasil relatou o primeiro caso suspeito de sarampo e enfrentou, assim, a reintrodução do vírus do sarampo, com a ocorrência de surtos em 11 estados (BRASIL, 2019b). 
No ano de 2019, ocorreram 15.914 casos de sarampo confirmados no Brasil, com total de 15 óbitos confirmados, sendo que apenas dois destes apresentaram registro de vacinação contra o sarampo (BRASIL, 2019b).

No estado do Paraná, de acordo com a Situação Epidemiológica do Sarampo 2019/2020, com atualização na segunda quinzena do mês de junho de 2020, notificaram-se 3.433 casos, destes, 1.536 confirmados, sem a ocorrência de óbitos e, 1.020 ainda estavam em investigação e 877 descartados (PARANÁ, 2020).

O retorno do sarampo para o Brasil mostra a carência de vacinação dos imigrantes associada à queda de cobertura vacinal contra a doença no país. As autoridades brasileiras seguem as estratégias do Plano Estratégico Global de Luta contra sarampo e rubéola (2012- 2020) que estabelece um conjunto de ações para atingir as metas de eliminação dessas doenças (MOURA et al., 2018).

Entre as medidas de controle a serem tomadas contra a propagação do sarampo, tem-se a obrigatoriedade da notificação imediata em até 24 horas para as secretarias municipais, regionais de saúde, coleta de amostra (soro, swab e urina), preferencialmente no quinto dia do início do exantema, isolamento domiciliar, bloqueio vacinal seletivo, conforme o Programa Nacional de Imunização (PNI) (PARANÁ, 2020).

De acordo com a Portaria n 204/2016, do Ministério da Saúde (MS), a notificação compulsória pode ser realizada por profissionais de saúde responsáveis pelas unidades de saúde pública ou privada e é uma comunicação obrigatória à autoridade de saúde (BRASIL, 2016). No entanto, ainda existe número elevado de subnotificações, fato que pode estar relacionado à conduta dos profissionais e carência de treinamento (MELO et al., 2018).

Ademais, a ampliação da cobertura vacinal nos estados brasileiros está entre as principais medidas de prevenção para redução dos casos de sarampo. Ao considerar o desconhecimento da população acerca da importância da vacinação, faz-se imprescindível que os profissionais de saúde elaborem estratégias que contribuam para o ensino-aprendizagem dos usuários (FERREIRAet al., 2019).

Diante desse cenário, a questão norteadora do estudo foi: qual o perfil dos casos de sarampo notificados em uma regional de saúde brasileira? Logo, objetivou-se caracterizar os casos de sarampo notificados em Regional de Saúde do interior do Paraná, Brasil.

\section{MATERIAL E MÉTODO}

Pesquisa documental e retrospectiva, com abordagem quantitativa. Analisaram-se todas as notificações de sarampo, registradas no Sistema de Informação de Agravos de Notificação (SINAN), da área de abrangência da Regional de Saúde, entre junho de 2018 e junho de 2020.

Estabeleceram-se, como critério de inclusão, todas as fichas de notificação de casos de sarampo registradas no SINAN, entre junho de 2018 e junho de 2020. Excluíram-se as fichas de notificação preenchidas no período anterior à coleta, aquelas com dados incompletos e/ou que contemplaram dados referentes à rubéola.

Salienta-se que houve dispensa do Termo de Consentimento Livre e Esclarecido (TCLE), uma vez que a pesquisa apresenta caráter documental.

A pesquisa foi aprovada pelo Comitê de Ética em Pesquisa Envolvendo Seres Humanos (CEPEH), sob parecer $n^{\circ}$ 2.338.550. Preservaram-se os aspectos éticos e legais, de acordo com a Resolução do Conselho Nacional de Saúde nº 466/2012. 
O instrumento de coleta de dados foi elaborado pelas próprias pesquisadoras, por meio da obtenção de dados da Ficha de Investigação de Doenças Exantemáticas Febris (Sarampo/ Rubéola) do SINAN e contempla as variáveis sociodemográficas (sexo, idade, raça/cor, nível de escolaridade, zona de residência), os dados complementares do caso (confirmação de imunização contra sarampo e rubéola, se teve contato com caso suspeito ou confirmado, sinais e sintomas, se ocorreu hospitalização, realização de exame sorológico, isolamento viral, amostra clínica coletada e etiologia, se foi realizado bloqueio vacinal e em qual intervalo de tempo, classificação final e qual o critério de confirmação ou descarte e qual a evolução do caso) e, ainda, a Unidade de Saúde notificadora e o período da notificação.

Os dados coletados entre julho e agosto de 2020 foram transferidos para planilha do programa Excel e, posteriormente, submetidos à análise estatística descritiva. Empregou-se o programa Statistical Package for the Social Sciences (SPSS), versão 25.0, para avaliação das frequências absolutas e relativas.

\section{RESULTADOS}

Entre o período de junho de 2018 e junho de 2020, notificaram-se 49 casos de sarampo. Houve predomínio de notificações em Centros de Saúde, com 79,6\%; e no ano de 2019, ocorreram o maior número de notificações $(55,1 \%)$.

Do total de casos, dois $(4,1 \%)$ foram confirmados. Em relação ao critério de confirmação ou descarte, prevaleceu o laboratorial, com 87,5\%. Quanto à evolução dos casos, 61,2\% obtiveram cura (Tabela 1).

Tabela 1 - Casos de notificação de sarampo na Regional de Saúde, Francisco Beltrão, PR, Brasil, 2020.

\begin{tabular}{|c|c|c|}
\hline Variáveis & $\mathbf{N}$ & $\%$ \\
\hline \multicolumn{3}{|l|}{ Ano da notificação } \\
\hline 2018 & 16 & 32,7 \\
\hline 2019 & 27 & 55,1 \\
\hline 2020 & 6 & 12,2 \\
\hline \multicolumn{3}{|l|}{ Unidade notificadora } \\
\hline Centro de Saúde & 39 & 79,6 \\
\hline Unidade Básica/ ESF & 8 & 16,3 \\
\hline Hospital & 2 & 4,1 \\
\hline \multicolumn{3}{|l|}{ Classificação final } \\
\hline Sarampo & 2 & 4,1 \\
\hline Descartado & 47 & 95,9 \\
\hline \multicolumn{3}{|c|}{ Critério de confirmação ou descarte } \\
\hline Laboratorial & 42 & 85,7 \\
\hline Clínico-epidemiológico & 4 & 8,2 \\
\hline \multicolumn{3}{|l|}{ Evolução do caso } \\
\hline Cura & 30 & 61,2 \\
\hline Não informado & 19 & 38,8 \\
\hline
\end{tabular}

Fonte: Coleta de dados, 2020.

A Tabela 2 retrata as características sociodemográficas dos indivíduos, situação vacinal e histórico de contato com casos suspeitos e confirmados de sarampo ou rubéola.

Ao considerar as características sociodemográficas, observou-se maior incidência de casos na população masculina (57,1\%). Quanto à faixa etária, houve destaque para idade escolar (36,7\%) e 
lactante (32,7\%). A raça branca foi predominante para 81,6\% das notificações. Referente à escolaridade, a opção "não se aplica" foi a mais empregada $(65,3 \%)$. No que tange à zona de residência, prevaleceu a urbana (85,7\%). Ainda, observou-se que 59,2\% estavam vacinados e 57,1\% não tiveram contato com caso suspeito ou confirmado de sarampo ou rubéola.

Tabela 2 - Dados sociodemográficos, situação vacinal e histórico de contato dos indivíduos, segundo casos de sarampo notificados na Regional de Saúde, Francisco Beltrão, PR, Brasil, 2020.

\begin{tabular}{|c|c|c|}
\hline Variáveis & $\mathbf{N}$ & $\%$ \\
\hline \multicolumn{3}{|l|}{ Sexo } \\
\hline Feminino & 21 & 42,9 \\
\hline Masculino & 28 & 57,1 \\
\hline \multicolumn{3}{|l|}{ Faixa etária } \\
\hline Lactante & 16 & 32,7 \\
\hline Pré-escolar & 2 & 4,1 \\
\hline Escolar & 18 & 36,7 \\
\hline Adolescente & 4 & 8,2 \\
\hline Adulto & 8 & 16,3 \\
\hline Idoso & 1 & 2,0 \\
\hline \multicolumn{3}{|l|}{ Raça/ cor } \\
\hline Branca & 40 & 81,6 \\
\hline Amarela & 1 & 2,0 \\
\hline Parda & 8 & 16,3 \\
\hline \multicolumn{3}{|l|}{ Escolaridade } \\
\hline Ensino fundamental incompleto & 5 & 10,2 \\
\hline Ensino fundamental completo & 2 & 4,1 \\
\hline Ensino médio incompleto & 2 & 4,1 \\
\hline Ensino médio completo & 2 & 2,0 \\
\hline Educação Superior incompleta & 1 & 2,0 \\
\hline Educação superior completa & 1 & 2,0 \\
\hline Ignorado & 1 & 2,0 \\
\hline Não informado & 4 & 8,2 \\
\hline Não se aplica & 32 & 65,3 \\
\hline \multicolumn{3}{|l|}{ Zona } \\
\hline Urbana & 42 & 85,7 \\
\hline Rural & 5 & 10,2 \\
\hline Não informado & 2 & 4,1 \\
\hline \multicolumn{3}{|l|}{ Situação Vacinal } \\
\hline Sim & 29 & 59,2 \\
\hline Não & 18 & 36,7 \\
\hline Ignorado & 2 & 4,1 \\
\hline \multicolumn{3}{|c|}{ Contato com caso suspeito ou confirmado de sarampo ou rubéola } \\
\hline Domicílio & 1 & 2,0 \\
\hline Vizinhança & 1 & 2,0 \\
\hline Creche/ escola & 1 & 2,0 \\
\hline Outro Estado/ Município & 1 & 2,0 \\
\hline Sem história de contato & 28 & 57,1 \\
\hline Ignorado & 17 & 34,7 \\
\hline
\end{tabular}

Fonte: Dados da pesquisa, 2020.

Disponível em: http://www.revistas2.vepg.br/index.php/biologica 
Em relação à sintomatologia, todos os indivíduos apresentaram febre e exantema (100\%), seguidos de coriza nasal (53,1\%). A hospitalização não foi necessária para 87,8\% dos casos.

A respeito dos exames sorológicos, para as primeiras sorologias IgM e IgG, constatou-se maior prevalência para não reagente, 42,0\% e 20,0\%, respectivamente. No entanto, de acordo com as notificações, 6,1\% dos indivíduos apresentaram reagentes para anticorpos IgM na primeira coleta. No que tange à segunda sorologia, ambas não foram informadas (85,7\%). Para os exames de reteste IgM e IgG, evidenciou-se maior frequência da variável "não informada" (69,4\%).

O isolamento viral foi realizado com amostras de sangue total para 57,1\% dos casos de sarampo. Quanto à etiologia do vírus, houve predomínio do sarampo selvagem (49,0\%). Sobre o bloqueio vacinal, evidenciou-se que os sujeitos que foram submetidos a esta imobilização também apresentaram a mesma porcentagem daqueles que não o realizaram (36,7\%). O intervalo de tempo predominou como "não informado" (53,1\%), conquanto, 20,5\% realizaram em até 72 horas.

Tabela 3 - Distribuição dos dados complementares dos casos de sarampo notificados na Regional de Saúde, Francisco Beltrão, PR, Brasil, 2020.

\begin{tabular}{|c|c|c|}
\hline Variáveis & $\mathbf{N}$ & $\%$ \\
\hline \multicolumn{3}{|l|}{ Exantema } \\
\hline Sim & 49 & 100 \\
\hline \multicolumn{3}{|l|}{ Febre } \\
\hline Sim & 49 & 100 \\
\hline \multicolumn{3}{|l|}{ Tosse } \\
\hline Sim & 21 & 42,9 \\
\hline Não & 26 & 53,1 \\
\hline Ignorado & 2 & 4,1 \\
\hline \multicolumn{3}{|l|}{ Coriza } \\
\hline Sim & 26 & 53,1 \\
\hline Não & 21 & 42,9 \\
\hline Ignorado & 2 & 4,1 \\
\hline \multicolumn{3}{|c|}{ Conjuntivite } \\
\hline Sim & 20 & 40,8 \\
\hline Não & 26 & 53,1 \\
\hline Ignorado & 3 & 6,1 \\
\hline \multicolumn{3}{|l|}{ Artralgia } \\
\hline Sim & 14 & 28,6 \\
\hline Não & 30 & 61,2 \\
\hline Ignorado & 5 & 10,2 \\
\hline \multicolumn{3}{|l|}{ Gânglio } \\
\hline Sim & 6 & 12,2 \\
\hline Não & 41 & 83,7 \\
\hline Ignorado & 2 & 4,1 \\
\hline \multicolumn{3}{|c|}{ Dor retro ocular } \\
\hline Sim & 14 & 28,6 \\
\hline Não & 30 & 61,2 \\
\hline Ignorado & 5 & 10,2 \\
\hline
\end{tabular}


continuação

\section{Variáveis}

\section{Ocorreu hospitalização}

$$
\text { Sim }
$$

Não informado

\begin{tabular}{|l|l|}
\hline 5 & 10,2 \\
\hline 43 & 87,8 \\
\hline 1 & 2,0 \\
\hline
\end{tabular}

\section{Sorologia $1 \lg M$}

Reagente

Não reagente

Inconclusivo

Não realizado

Não informado

\begin{tabular}{|l|l|}
\hline 3 & 6,1 \\
\hline 42 & 85,7 \\
\hline 3 & 6,1 \\
\hline 2 & 4,1 \\
\hline 1 & 2,0 \\
\hline
\end{tabular}

Sorologia 1 IgG

Reagente

Não reagente

Não realizado

Não informado

\begin{tabular}{|l|l|}
\hline 14 & 28,6 \\
\hline 20 & 40,8 \\
\hline 11 & 22,4 \\
\hline 4 & 8,2 \\
\hline
\end{tabular}

\begin{tabular}{|c|c|c|}
\hline Reagente & 1 & 2,0 \\
\hline Não reagente & 4 & 8,2 \\
\hline Não realizado & 2 & 4,1 \\
\hline Não informado & 42 & 85,7 \\
\hline \multicolumn{3}{|l|}{ Sorologia 2 lgG } \\
\hline Reagente & 2 & 4,1 \\
\hline Não reagente & 3 & 6,1 \\
\hline Não realizado & 2 & 4,1 \\
\hline Não informado & 42 & 85,7 \\
\hline \multicolumn{3}{|l|}{ Reteste IgM } \\
\hline Não reagente & 1 & 2,0 \\
\hline Não realizado & 14 & 28,6 \\
\hline Não informado & 34 & 69,4 \\
\hline \multicolumn{3}{|l|}{ Reteste IgG } \\
\hline Não reagente & 1 & 2,0 \\
\hline Não realizado & 14 & 28,6 \\
\hline Não informado & 34 & 69,4 \\
\hline \multicolumn{3}{|l|}{ Sangue } \\
\hline Sim & 28 & 57,1 \\
\hline Não & 10 & 20,4 \\
\hline Não realizado & 5 & 10,2 \\
\hline \multicolumn{3}{|l|}{ Urina } \\
\hline Sim & 16 & 32,7 \\
\hline Não & 23 & 46,9 \\
\hline Não realizado & 4 & 8,2 \\
\hline Ignorado & 6 & 12,2 \\
\hline
\end{tabular}

\section{Sorologia $2 \lg M$}

continua 
conclusão

\begin{tabular}{|c|c|c|}
\hline Variáveis & $\mathbf{N}$ & $\%$ \\
\hline \multicolumn{3}{|l|}{ Secreção } \\
\hline Sim & 18 & 36,7 \\
\hline Não & 20 & 40,8 \\
\hline Não realizado & 9 & 18,4 \\
\hline Ignorado & 2 & 4,1 \\
\hline \multicolumn{3}{|l|}{ Líquor } \\
\hline Sim & 2 & 4,1 \\
\hline Não & 37 & 75,5 \\
\hline Não realizado & 4 & 8,2 \\
\hline Ignorado & 6 & 12,2 \\
\hline \multicolumn{3}{|l|}{ Etiologia viral } \\
\hline Vírus sarampo selvagem & 24 & 49,0 \\
\hline Vírus sarampo vacinal & 2 & 4,1 \\
\hline Outros & 2 & 4,1 \\
\hline Não realizado & 21 & 42,9 \\
\hline \multicolumn{3}{|l|}{ Realizou bloqueio vacinal } \\
\hline Sim & 18 & 36,7 \\
\hline Não & 18 & 36,7 \\
\hline Não, todos vacinados & 9 & 18,4 \\
\hline Ignorado & 4 & 8,2 \\
\hline \multicolumn{3}{|l|}{ Qual o intervalo do tempo } \\
\hline Até 72h & 13 & 26,5 \\
\hline Após 72h & 4 & 8,2 \\
\hline Não realizou & 1 & 2,0 \\
\hline Não informado & 26 & 53,1 \\
\hline Ignorado & 5 & 10,2 \\
\hline
\end{tabular}

Fonte: Dados da pesquisa, 2020.

\section{DISCUSSÃO}

Evidenciou-se que em 2019 ocorreu o maior número de notificações. Durante o período da coleta de dados, apenas dois casos de sarampo foram confirmados. No estado do Paraná, no ano de 2019, dados preliminares indicaram a ocorrência de 2.082 casos, destes 648 foram confirmados. Esse aumento considerável do número de casos, possivelmente, justifica-se pelo movimento migratório dos venezuelanos e pela situação vacinal da população brasileira (PARANÁ, 2019).

Constatou-se maior prevalência de notificações por centro de saúde. Sem dúvida, as notificações são imprescindíveis para o planejamento das ações de vigilância em saúde. No entanto, muitas vezes, são realizadas de maneira incorreta, com falhas de preenchimento e/ou com descumprimento da frequência estabelecida, o que implica dados não fidedignos da realidade epidemiológica (MELO et al., 2018). Quanto à evolução do caso, identificou-se predomínio para cura. Faz-se importante considerar que a maioria dos casos não foi confirmada, o que pode justificar esse dado. 
No que tange aos dados sociodemográficos, parte considerável dos indivíduos era do sexo masculino, idade escolar, branca, com ensino fundamental incompleto e residente da zona urbana. Em estudo no estado do Pará, no ano de 2018, a maioria dos casos notificados de sarampo se concentrava na faixa etária de um a quatro anos (18,3\%). E, sobre o sexo, contrariamente, nesse estudo, a maioria era do sexo feminino (50\%) (BRASIL, 2019b).

Sobre a vacinação contra o sarampo, identificou-se que potencial parte dos indivíduos estava vacinada. Segundo o Ministério da Saúde, o Brasil alcançou a meta de vacinação do ano de 2019, com 99,4\% de crianças de um ano de idade vacinadas no país, sendo considerado o melhor resultado dos últimos cinco anos. Entretanto, oito estados e o Distrito Federal não atingiram a meta mínima de 95\% (BRUZZI et al., 2020).

O órgão, ainda, ressalta que esse resultado satisfatório é consequência das Campanhas Nacionais de Vacinação contra o sarampo. De acordo com a Organização Pan-Americana da Saúde, o crescente aumento dos surtos é registrado em países que têm baixa cobertura vacinal contra o sarampo, seja em períodos anteriores ou na atualidade, causando vulnerabilidade na população. Coincidentemente, registraram-se extensos casos de surto, mesmo em países que atingiram as metas de vacinação, sendo resultado da discrepância e de brechas enfrentadas durante o período vacinal (BRUZZI et al., 2020).

Pelos dados aqui apresentados, verificou-se a ocorrência de dois casos confirmados de sarampo, o que pode preditar possíveis lacunas. Embora o sarampo não tenha acometido número considerável de pessoas, faz-se necessária a vacinação intensificada para combatê-lo. Para a Organização Mundial da Saúde e a Organização Pan-Americana da Saúde (OPAS), a melhor forma de prevenção do sarampo ocorre por meio da vacinação, de modo a se manter cobertura homogênea de $95 \%$ com a primeira e segunda doses da vacina contra sarampo, caxumba e rubéola, em todos os municípios (FERREIRA et al., 2019).

Sabe-se que o sarampo é uma doença potencialmente grave, uma vez que pode deprimir a resposta imune e contribuir para manifestação de outros patógenos, evoluindo com complicações infecciosas bacterianas, inclusive de fácil transmissibilidade (MEDEIROS, 2020). Quando associado a uma cobertura vacinal inadequada, existe risco de possível recidiva e implicações para saúde da população (MOURA et al., 2018).

Um dos possíveis motivos para reintrodução do vírus no Brasil foi a certificação do país em relação à erradicação do sarampo, em 2016, e o êxito do Programa Nacional de Vacinação, que gerou a errônea sensação de estar "livre" da doença, contribuindo, de forma indireta, para a população desconsiderar a necessidade da vacinação. Para tanto, outros fatores também podem ter contribuído, como a incompatibilidade nos horários de funcionamento das unidades de saúde, déficit de informação a respeito da enfermidade, disseminação de notícias falsas por aplicativos, gerando insegurança sobre a eficácia das vacinas (LEITE; RAMALHO; SOUSA, 2019).

Acerca da sintomatologia do sarampo, evidenciou-se que todos os casos notificados apresentaram exantema. O sarampo pode se manifestar em três períodos: período prodrômico, exantemático e de convalescença. O período prodrômico perdura por seis dias e a sintomatologia inicial é febre acompanhada de tosse e corrimento seromucoso no nariz. No período exantemático, ocorre a acentuação dos sintomas destacados e aparecem as manchas de cor avermelhada espalhadas pelo corpo, no sentido céfalo-caudal, geralmente antecedidas de elevações esbranquiçadas, acinzentadas ou mesmo azuladas na língua, também conhecidas como sinal de Koplik. No terceiro e último período, 
chamado de período de convalescença ou de descamação furfurácea, as manchas vão se tornando escuras e acontece a descamação (CARVALHO et al., 2019).

A respeito dos exames sorológicos, para as primeiras sorologias IgM e IgG, constatou-se maior prevalência para não reagente, conquanto as demais, em maioria, não foram realizadas.

O diagnóstico laboratorial pode ser realizado por meio da sorologia para detecção de anticorpos IgM e IgG específicos. Os anticorpos específicos da classe IgM podem ser detectados no sangue, na fase aguda da doença, desde os primeiros dias até quatro semanas após o aparecimento do exantema. A presença de anticorpos da classe IgM indica infecção recente pelo vírus do sarampo. Os anticorpos específicos da classe IgG começam a aparecer logo após a fase aguda da doença, desde os primeiros dias e, geralmente, continuam sendo detectados muitos anos após a infecção (XAVIER et al., 2019).

O isolamento viral foi realizado, em maioria, com amostras de sangue total. Quanto à etiologia do vírus, constatou-se predomínio do sarampo selvagem. Salienta-se que o vírus do sarampo pode ser diagnosticado precocemente por meio da realização de exames laboratoriais, como o ensaio imunoenzimático (ELISA), ou por meio da técnica RT-PCR, com amostras de diferentes espécimes clínicos, coletadas preferencialmente, nos três primeiros dias do início do exantema. Por sua vez, o isolamento viral permite estabelecer o padrão genético do vírus circulante no país, se vírus selvagem ou vacinal, permitindo a diferenciação entre casos autóctones e importados (CARVALHO et al., 2019).

No que concerne ao bloqueio vacinal, evidenciou-se que os sujeitos que foram submetidos a ele também apresentaram a mesma porcentagem daqueles que não o realizaram, sendo que o intervalo de tempo predominou como "não informado".

O bloqueio vacinal deve ser realizado no prazo de 72 horas após a notificação do caso, a fim de eliminar a cadeia de transmissão e reduzir os suscetíveis. Esta atividade é decisiva em surtos de sarampo e independe de resultado laboratorial (DIVE, 2018).

Enfatiza-se, ainda, que o bloqueio é seletivo e deve ser realizado em todos os locais que o caso frequentou, abrangendo contactantes do mesmo domicílio do caso suspeito (vizinhos próximos, creches, escolas, faculdades, academias, dentre outros). Todos os indivíduos que não têm histórico de vacina e/ou comprovante vacinal devem ser vacinados, considerando-se até 18 dias antes do aparecimento do exantema (DIVE, 2018).

Quanto às limitações do estudo, destaca-se a presença de informações reportadas como "ignorado ou não se aplica" pelos profissionais de saúde, isso quando os campos não são informados ou preenchidos na notificação.

\section{CONCLUSÕES}

Houve reintrodução do vírus do sarampo na Regional de Saúde estudada. Assim, reitera-se que conhecer o perfil epidemiológico dos casos poderá permitir o desenvolvimento de ações de promoção e prevenção em saúde mais específicas.

Desse modo, a pesquisa poderá contribuir indiretamente para diminuição dos casos de sarampo, possíveis óbitos e complicações, além de redução dos custos hospitalares e internações relacionadas ao agravo. 
Salienta-se, também, que, mesmo que o número de casos confirmados seja pouco incidente, faz-se importante que sejam implementadas novas formas de manejo, principalmente campanhas vacinais mais abrangentes, que garantam aumento da cobertura vacinal e erradicação do vírus.

Ademais, ao considerar que a reintrodução do vírus é recente no estado, sugere-se a realização de novos estudos para identificar e caracterizar o surgimento de novos casos.

\section{REFERÊNCIAS}

BRANCO, V.G.C.; MORGADO. F.E. O surto de sarampo e a situação vacinal no brasil. Rev. de Medicina de Família e Saúde Mental, v. 1, n. 1, p. 74-88, 2019. Disponível em: https://www.unifeso. edu.br/revista/index.php/medicinafamiliasaudemental/article/view/1594/634. Acesso em: 22 out. 2020.

BRASIL. Ministério da Saúde. Secretaria de Vigilância em Saúde. Coordenação-Geral de Desenvolvimento da Epidemiologia em Serviços. Guia de Vigilância em Saúde. 3 ed. Brasília: Ministério da Saúde, 2019a. Disponível em: https://portalarquivos2.saude.gov.br/images/pdf/2019/ junho/25/guia-vigilancia-saude-volume-unico-3ed.pdf. Acesso em: 09 set. 2020.

BRASIL. Ministério da Saúde. Secretaria de Vigilância em Saúde. Informe 37: Situação do Sarampo no Brasil 2018-2019. Brasília: Ministério da Saúde, 2019b. Disponível em: https://portalarquivos2. saude.gov.br/images/pdf/2019/marco/19/Informe-Sarampo-n37-19mar19aed.pdf. Acesso em: 10 ago. 2020.

BRASIL, Ministério da Saúde. Informe 32: Situação do Sarampo no Brasil 2018. Braślia: Ministério da Saúde, 2018. Disponível em: https://portalarquivos2.saude.gov.br/images/pdf/2018/novembro/28/ Informe-Sarampo-n32.pdf. Acesso em: 12 out. 2020.

BRASIL, Ministério da Saúde. Portaria n 204, de 17 de fevereiro de 2016. Define a Lista Nacional de Notificação Compulsória de doenças, agravos e eventos de saúde pública nos serviços de saúde públicos e privados em todo o território nacional, nos termos do anexo, e dá outras providências. Diário Oficial da União, Brasília, DF, 17 fev. 2016.

BRUZZI, C.L.L. et al. Compreendendo o retorno do surto de sarampo no Brasil em 2019 e dados epidemiológicos até fevereiro de 2020. Brazilian Journal of Surgery and Clinical Research, v. 32, n. 2, p. 111-117, set./nov. 2020. Disponível em: https://www.mastereditora.com.br/ periodico/20201004_093724.pdf. Acesso em: 15 set. 2020.

CARVALHO, A.L. et al. Sarampo: Atualizações e reemergência. Rev. Med. Minas Gerais, v. 29, p. 8085, 2019. Disponível em: http://rmmg.org/artigo/detalhes/2629. Acesso em: 02 jun. 2020.

DIVE. Diretoria de Vigilância Epidemiológica. Noła Técnica n 004/2018. Dispõem sobre a intensificação das ações de vigilância epidemiológica do sarampo, mediante risco de reintrodução do vírus no Brasil. Florianópolis, SC, 09 jul. 2018. Disponível em: http://dive.sc.gov.br/ conteudos/NotaDeAlerta2018/NotaSarampoN4/NotaTecnicaN4.pdf. Acesso em 17 out. 2020.

FERREIRA, R.S.B. et al. Correlação entre cobertura vacinal e notificações por sarampo no Distrito Federal. Rev. Eletrônica Acervo Saúde, v. 11, n. 17, p. 1-8, 2019. DOI: https://doi.org/10.25248/reas. el654.2019

LEITE, F.S. L.P.; RAMALHO, M.I.L.; SOUSA, M.N.A. Evolução do sarampo no estado de Roraima e a atual situação vacinal no Brasil. Rev. Ciência e Desenvolvimento, Vitória da Conquista, v.12, n.1, p.129-140, jan./abr. 2019. Disponível em: https://www.researchgate.net/publication/331618424_ 
EVOLUCAO_DO_SARAMPO_NO_ESTADO_DE_RORAIMA_E_A_ATUAL_SITUACAO_VACINAL_NO_ BRASIL. Acesso em: 12 ago. 2020.

MEDEIROS, E.A.S. Entendendo o ressurgimento e o controle do sarampo no Brasil. Acta Paul. Enferm., São Paulo, v. 33, 2020. DOl: https://doi.org/10.37689/acta-ape/2020edt0001

MELO, M.A.S. et al. Percepção dos profissionais de saúde sobre os fatores associados à subnotificação no Sistema Nacional de Agravos de Notificação. Rev. Adm. Saúde, v. 18, n. 71, p. 1-17, abr./jun. 2018. DOl: http://dx.doi.org/10.23973/ras.71.104

MOURA, A.D.A. et al. Estratégias e resultados da vacinação no enfrentamento da epidemia de sarampo no estado do Ceará, 2013-2015. Epidemol. Serv. Saúde, Brasília, v. 27. n. 1, p. 1-8, 2018. DOI: https://doi.org/10.5123/s1679-49742018000100010

PARANÁ. Secretaria de Estado da Saúde. Diretoria de Atenção e Vigilância em Saúde.

Coordenadoria de Vigilância Epidemiológica. Divisão de Vigilância das Doenças Transmissíveis. Informe Epidemiológico Sarampo - SE 31/2019 a SE 25/2020. Curitiba: Secretaria de Estado da Saúde, 2020. Disponível em: https://www.saude.pr.gov.br/sites/default/arquivos_restritos/files/ documento/2020-06/sarampo_boletim_38.pdf. Acesso em: 03 jul. 2020.

PARANÁ. Secretaria de Estado da Saúde. Diretoria de Atenção e Vigilância em Saúde.

Coordenadoria de Vigilância Epidemiológica. Divisão de Vigilância das Doenças Transmissíveis. Informe Epidemiológico Sarampo - SE 31 a 50. Curitiba: Secretaria de Estado da Saúde, 2019. Disponível em: https://www.saude.pr.gov.br/sites/default/arquivos_restritos/files/ documento/2020-05/sarampo_boletim_17.pdf. Acesso em: 07 abr. 2020.

XAVIER, A.L.R. et al. Diagnóstico clínico, laboratorial e profilático do sarampo no Brasil. J. Bras. Patol. Med. Lab., Rio de Janeiro, v. 55, n. 4, p. 390-401, jul./ago. 2019. DOl: https://doi.org/10.5935/16762444.20190035 